Mini Review

\section{Corrosive base neutralization process: Review}

\author{
Jhansi Rani* \\ M.Pharm, St.Anns Collage of Pharmcy, Andhra Pradesh, India
}

\section{Summary}

A balance response is the point at which a corrosive and a base respond to shape water and a salt and includes the mix of $\mathrm{H}+$ particles and $\mathrm{OH}$-particles to produce water. The balance of a solid corrosive and solid base has a pH equivalent to 7 .

\section{Presentation}

At the point when a powerless corrosive and feeble base respond with one another total balance doesn't happen because of inadequate ionization of the corrosive and base. A salt is any compound which can be gotten from the balance of a corrosive and a base. "Neutralization" is utilized on the grounds that the corrosive and base properties of $\mathrm{H}+$ and $\mathrm{OH}-a r e$ annihilated or killed. In the response, $\mathrm{H}+$ and $\mathrm{OH}-$ consolidate to frame $\mathrm{HOH}$ or $\mathrm{H}_{2} \mathrm{O}$ or water atoms. A balance is a kind of twofold substitution response. A salt is the result of a corrosive base response and is a lot more extensive term then basic table salt as appeared in the primary response. Coming up next are a few instances of balance responses to frame salts.
a. $\mathrm{HCl}+\mathrm{NaOH}->\mathrm{NaCl}+\mathrm{HOH}$
b. $\mathrm{H}_{2} \mathrm{SO}_{4}+2 \mathrm{NH}_{4} \mathrm{OH}->\left(\mathrm{NH}_{4}\right) 2 \mathrm{SO}_{4}+2 \mathrm{HOH}$
c. $2 \mathrm{NaOH}+\mathrm{H}_{2} \mathrm{CO}_{3}->\mathrm{N}_{2} \mathrm{CO}_{3}+2 \mathrm{NaOH}$
d. Lime water: $\mathrm{Ca}(\mathrm{OH}) 2+\mathrm{H}_{2} \mathrm{CO}_{3}->\mathrm{CaCO}_{3}+2 \mathrm{HOH}$

\section{Materials and methods}

While balance responses are generally indistinguishable from various perspectives, it is valuable to take a gander at those including just solid acids and bases independently from those including a frail corrosive, a feeble base, or both.

\section{Solid acid-strong base reactions}

At the point when equivalent measures of a solid corrosive, for example, hydrochloric corrosive are blended in with a solid base, for example, sodium hydroxide, the outcome is an unbiased arrangement. All in all, the results of the response $(\mathrm{aq})+\mathrm{H}_{2} \mathrm{O}(\mathrm{l})$

\section{More Information}

*Address for Correspondence: Jhansi Rani, M.Pharm, St.Anns Collage of Pharmacy, Andhra Pradesh, India, Email: jhanugra2017@gmail.com

Submitted: November 13, 2020

Approved: December 01, 2020

Published: December 02, 2020

How to cite this article: Rani J. Corrosive base neutralization process: Review. Ann Adv Chem. 2020; 4: 001-002.

DOI: 10.29328/journal.aac.1001021

Copyright: @ 2020 Rani J. This is an open access article distributed under the Creative Commons Attribution License, which permits unrestricted use, distribution, and reproduction in any medium, provided the original work is properly cited.

\section{Check for updates}

OP OPEn Access

don't have the qualities of either a corrosive or a base. Here is the reasonable sub-atomic condition [1].

$$
\mathrm{HCl}(\mathrm{aq})+\mathrm{NaOH}(\mathrm{aq}) \rightarrow \mathrm{NaCl}(\mathrm{aq})+\mathrm{H}_{2} \mathrm{O}(\mathrm{l})
$$

A balance response is a response wherein a corrosive and a base respond in a watery answer for produce a salt and water. Note that the balance response above is an illustration of a twofold substitution response. The watery sodium chloride that is delivered in the response is known as a salt. A salt is an ionic compound made out of a cation from a base and an anion from a corrosive. Notwithstanding, on the grounds that basically any anion or cation can be matched with hydrogen or hydroxide particles to make a corrosive or base, the term salt can be utilized to depict any ionic compound, and the two terms are frequently utilized reciprocally. Review that synthetic responses happening in fluid arrangement can regularly be composed as a net ionic condition. The full ionic condition for the balance of hydrochloric corrosive with sodium hydroxide is composed as follows:

$$
\mathrm{H}+(\mathrm{aq})+\mathrm{Cl}-(\mathrm{aq})+\mathrm{Na}+(\mathrm{aq})+\mathrm{OH}-(\mathrm{aq}) \rightarrow \mathrm{Na}+(\mathrm{aq})+\mathrm{Cl}-
$$

Since the corrosive and base are both solid, they are completely ionized, so they can be composed as particles. Since the $\mathrm{NaCl}$ item is additionally water-solvent, it stays separated. The sodium and chloride particles are observer particles, leaving the accompanying net ionic response:

$$
\mathrm{H}+(\mathrm{aq})+\mathrm{OH}-(\mathrm{aq}) \rightarrow \mathrm{H}_{2} \mathrm{O}(\mathrm{l})
$$

All balance responses between a solid corrosive and a 
solid base streamline to this net ionic condition. Consider the possibility that the corrosive is a diprotic corrosive, for example, sulfuric corrosive. The fair atomic condition presently includes a 1:2 proportion among corrosive and base.

$$
\mathrm{H}_{2} \mathrm{SO}_{4}(\mathrm{aq})+2 \mathrm{NaOH}(\mathrm{aq}) \rightarrow \mathrm{Na}_{2} \mathrm{SO}_{4}(\mathrm{aq})+2 \mathrm{H}_{2} \mathrm{O}(\mathrm{l})
$$

All together for the response to be a full balance, twice the same number of moles of $\mathrm{NaOH}$ should respond with the $\mathrm{H}_{2} \mathrm{SO}_{4}$. The sodium sulfate salt is dissolvable, thus the net ionic response is again the equivalent. Diverse mole proportions can happen when utilizing polypro spasm acids or bases that incorporate various hydroxide particles per recipe unit, for example, $\mathrm{Ca}(\mathrm{OH})_{2}$.

\section{Results and discussion}

\section{Kill acids and bases}

Spills of risky substances should be ingested, killed or controlled at the hour of the episode to keep up work environment security. Corrosive and base balance helps make spilled materials more secure to deal with and helps decline the expense of removal. The most ideal approach to decide whether a material is acidic or fundamental is to gauge its $\mathrm{pH}$. This can be cultivated with pH paper, substance markers or
pH meters. The pH scale measures from 0 to 14 . Synthetics with a pH of 0 to 3 are viewed as solid acids. Synthetic substances with a $\mathrm{pH}$ of 12 to 14 are viewed as solid bases. To be viewed as unbiased, a substance should have a $\mathrm{pH}$ of 7 . Acids regularly will have a sharp taste and a $\mathrm{pH}$ of under 7. There are two sorts of acids: mineral (inorganic) acids, for example, sulfuric, hydrochloric or nitric and carboxylic (natural) acids, for example, formic or acidic. To kill acids, a feeble base is utilized. Bases have a severe or astringent taste and a pH more noteworthy than 7. Regular bases are sodium hydroxide, potassium hydroxide and ammonium hydroxide. Bases are killed by utilizing a feeble corrosive.

\section{Conclusion}

Acids and bases don't just occur in logical labs; they are utilized in more places in the present society. Acids and bases are associated with our regular daily existence in everything from assimilation of food to the medication you take and furthermore in cleaning items you use.

\section{References}

1. Metcalf and Eddy. Wastewater Engineering, Treatment and Reuse. $4^{\text {th }}$ ed. New York: McGraw-Hill, 2003. 526-532. 